\title{
The Investigation of the Motor Skills of "U" Kategories Soccer Players Who Have Recreative Involvement in Other Sports
}

\author{
Ömer Can Göksu ${ }^{1}$, Selami Yüksek ${ }^{2}$, Cengiz Ölmez ${ }^{2}$ \\ ${ }^{1}$ Istanbul University, Faculty of Sports Science, Department Trainer Education, Turkey \\ ${ }^{2}$ Karadeniz Technical University, College of Physical Education and Sports, Department Trainer Education, \\ Turkey
}

Correspondence: Selami Yüksek, Karadeniz Technical University, College of Physical Education and Sports, Department Trainer Education, Turkey.

Received: November 29, 2017

doi:10.11114/jets.v6i2.2824
Accepted: December 31, 2017 Online Published: January 20, 2018

URL: https://doi.org/10.11114/jets.v6i2.2824

\begin{abstract}
This study was conducted to examine the effects of sports activities other than soccer on 10-15-year-old soccer players' motor skills. The sample included 146 registered soccer players in the U category (U10-U15) of the Turkish Football Federation's Aslantepe, Çeliktepe and Seyrantepe clubs. The players participated in this study on a voluntary basis. The players who participated in the study were divided into two age categories (10-12 and 13-15 years) and two groups, those who only played soccer (OS) and those involved in soccer and other sports (SAO). The study recorded the sociodemographic characteristics of the athletes, the sports they were interested in other than soccer, the weekly time they spent in different sports activities and the number of soccer training sessions they attended each week. The measurements for the study were completed in the first week of the preparation period at the beginning of the soccer season. All the participants were subjected to tests for speed, agility, horizontal jumping, endurance, and the motor tests that measured balance parameters, all of which are important for soccer. The study data were analyzed using SPSS 23.0 software. The study used the Kolmogorov-Smirnov test to determine whether the data had normal distributions. The parameters with normal distributions were analyzed using the t-test, while those without normal distributions were analyzed using the Mann-Whitney $U$ test. The threshold for statistical significance was $p<0.05$. Analysis of the data showed that there were statistically significant $(\mathrm{p}<0.05)$ differences between the motor skills test results of the players in SAO group and those in the OS group. Thus, having children get interested in multiple sports at a young age instead of only one, and including forms of play that feature the fundamental skills of different sports in their training programs will positively contribute to the development of their motor skills and improve their performance.
\end{abstract}

Keywords: children, performance, soccer, motor skills

\section{Introduction}

Human beings, by nature, have to move constantly. This was necessary to survive in difficult living conditions centuries ago (Zorba, 2001). Today, the concept of motion evokes terms such as sports, training, competition and performance. These terms change according to the purpose of sport for the individual and have been subject to examination in the literature. Forty years ago, training plans and programs were actually made up of techniques, tactics and hints from experts in the field. This method, which is called champion training, was abandoned in favor of scientific theory rather than producing champion knowledge (Muratlı et al, 2011). Scientific theories constituted the training basics, and over time, professionalization in the field led to examining the smallest units of training.

The general development of athletes should be in balance between versatile development and sports-specific development. Athletes' general development should be achieved by versatile training that is addressed to ensuring thorough physical development. As athletes grow up, the rate of sports-specific practices and skills should be increased, and they should be directed to more to-the-point (addressed to the branch) practices (Bompa and Haff, 2015). Therefore, strength, speed, endurance, quickness and balance should be developed to the maximal level. Known as basic motor skills, these competencies are the basic performance characteristics specific to sports and are a very important requirement for physical and physiological harmony in sports (Sevim, 2006).

Basic motor skills working in harmony determine the quality of coordination skills. The better the coordination, the 
shorter the time and the more efficiently the goal of an action can be achieved in sports. Since skill is in fact a result of coordination skills, these skills are a component of success in sports (Muratlı et al., 2011). The versatile and different types of exercises that contribute to children's development of coordination are an important basis for their progressive professionalization. Basic motor skills and coordination skills are necessary for all sports and are an important determinant of success. While motor skills affect sports performance, sports skills reciprocally affect motor skills. Speed is very important for a sprinter. Those who are fast are successful in sprint performance, but it is obvious that this performance has been improved by sprint training (Bompa and Haff, 2015) In this case, motor skills are in a position that both affects sports performance and affected by sports performance.

The specific goals for training are the development of both general (versatile) and specific (specific to one sports branch) motor skills. The fact that general motor skills are a factor in success in sports brings to mind the question, "Can trained motor skills in any sport affect success in another sport?" Therefore, the aim of this study was to examine the effects on 10-15-year-old soccer players' motor skills of the sports activities they were interested in other than soccer.

\section{Method}

\subsection{Study Group}

This study was carried out with 146 registered soccer players in the U category (U10-U15) of the Turkish Football Association's Aslantepe, Çeliktepe, and Seyrantepe clubs. The athletes participated the study on a voluntary basis with the written consent of their guardians in accord with the principles of the Declaration of Helsinki (World Medical Association, 2008). The players who participated in the study were divided into two age categories (10-12 and 13-15 years) and two groups, those who only played soccer (OS) and those involved in soccer and other sports (SAO). The study recorded their sociodemographic characteristics and the sports in which they were interested other than soccer, the weekly time they spent in different sports activities, and the number of training sessions they attended a week. The athletes who were involved in sports other than soccer for at least two hours a week were included in the SAO group, while those who were not involved in any sport other than soccer were included in the OS group.

\subsection{Data Collection}

All the measurements were performed in the İstanbul Kâğıthane Municipality's Seyrantepe Soccer Stadium in the first week of the preparation period (no-competition period) in two days between 10 a.m. and 5 p.m.

The height of the athletes was measured using a steel meter stick with a flat floor surface and a wall. Their weight was measured using a $0.1 \mathrm{~kg}$-sensitive electronic scale with their light clothes on. Body mass index (BMI) was calculated by dividing body weight in kilograms by the square of height in meters (James et al, 2005).

Prior to the motor skill measurements, all the athletes were subjected to a standard warm-up protocol that included approximately 5-7 minutes of jogging, stretching and short sprints at different levels. Before the tests, the researcher informed the participants orally and practically. The researcher also provided motivating feedback to the athletes to ensure their maximum productivity.

To determine the speed performance of the participants, 10 and 30-meter sprint tests were done using the New Test Power Time 300 brand photocell, which allows multiple speed measurements. This test provides information about the participants' anaerobic power, explosive power, rapid strength, and acceleration ability (Wood, 2008a). The participants were asked to run at their maximum speed after the go signal on a straight running area of 10 meters and 30 meters in length. The test was repeated twice for each participant, and their best results were recorded in second. The participants were allowed to rest completely between the two tests.

The study used the pro-agility (quickness) test to determine the athletes' quickness. A straight line was drawn 5 yards to the right and 5 yards to the left of the photocell. The test participants waited ready in front of the photocell with knees slightly bent, started the run when the light turned off and ran 15 yards between the right and left lines at their maximum speed. Both passes in front of the photocell were recorded as the first and second turning times. The test was repeated twice for each participant, and their best results were recorded in second. Five-minute rests were given between repetitions of the test (McGuigan, 2000).

The athletes did a horizontal jump test to determine vertical and horizontal axial leg forces, balance and coordination. The participants jumped as far as possible on the floor, with their toes on a line and arms behind them, knees slightly flexed and their bodies slightly bent forward. The distance from the athlete's heel to the starting line was measured. The test was repeated twice for each participant, and their best results were recorded as the performance value in centimeters (Maulder and Cronin, 2005).

A 20 meter shuttle run test with a high reliability coefficient $(\mathrm{rxy}=0.77)$ was used to determine the aerobic power of the participants (Dardouri et al., 2014). A 20-meter flat surface was used for the running area. The participants were 
instructed to reach the 20 -meter line with special shuttle run signals, each signal interval increasing by $0.5 \mathrm{~km} / \mathrm{min}$. The test was terminated for participants who were unable to reach the inner line in front of the 20-meter line before the signal was given two times in a row, and the total distance was recorded in meters (Leger and Lambert, 1982).

To determine the athletes' ability to balance, the flamingo balance test with a high confidence coefficient ( $\mathrm{rxy}=0.73)$ was used (Tsigilis et al, 2002). The researcher used a metal cable that was linear and inflexible. The cable was $50 \mathrm{~cm}$ long, 5 $\mathrm{cm}$ high and $3 \mathrm{~cm}$ wide. The string was fixed using two wooden supports that were $15 \mathrm{~cm}$ long and $4 \mathrm{~cm}$ wide. Each participant was asked to hold the hand of the assistant, to stand on one foot using their dominant foot, and to bend the other foot back and hold it with their hand. When the participant was ready, he left his assistant's hand, and the stopwatch was started at the same time. Each time the participant lost balance (by falling off the beam or letting go of the foot), the stopwatch was stopped and started again when participant was ready. The total number of balance losses during sixty seconds was recorded (Wood, 2008b). The test was done when the athletes were in rested condition.

\subsection{Data Analysis}

SPSS 23.0 statistical software was used for statistical analysis of the data. Initially, the researcher performed the Kolmogorov-Smirnov test to determine whether the data had a normal distribution. The general characteristics of the groups were determined using descriptive statistics. The researcher used the following tests to determine the level of significant differences between the results of the athletes who were involved only in soccer and those who were involved in other sports as well: independent samples t-test for the data with normal distributions (height, BMI, 10-30 meter sprint, pro-agility 1-2 turn and 20 meter shuttle run test in the 10-12 age group; height, weight, BMI, 10 meter sprint, pro-agility 1-2 turn, horizontal jump and 20 meter shuttle run in the 13-15 age group), and the Mann-Whitney U test for the data that did not have normal distributions (age, weight, soccer experience, horizontal jump and balance in the 10-12 age group; age, soccer experience,30 meter sprint and balance in the 13-15 age group). The mean values and standard deviations of the parameters of all participants were calculated.

\section{Results}

This section includes the demographic information, the sports of interest, and the results of the motor skills test measurements and comparisons for the 146 athletes in the study that were aged from 10 to 15 with a consideration of $10-12$ and $13-15$ age groups.

Table 1. The percentages of the participants' involvement in different sports

\begin{tabular}{ccccc}
\hline & $\mathbf{1 0 - 1 2}$ age group & \multicolumn{2}{c}{$\mathbf{1 3 - 1 5}$ age group } \\
& $\mathbf{n}$ & $\mathbf{\%}$ & $\mathbf{n}$ & $\mathbf{\%}$ \\
\hline Basketball & 12 & 24,5 & 20 & 20,6 \\
Track and Field & 8 & 16,3 & 7 & 7,2 \\
Boxing & 1 & 2,0 & 7 & 7,2 \\
Table tennis & - & - & 1 & 1,0 \\
Taekwondo & 6 & 12,2 & 8 & 8,2 \\
Volleyball & - & - & 5 & 5,2 \\
Swimming & 5 & 10,2 & 6 & 6,2 \\
Only Soccer & 17 & 34,7 & 43 & 44,3 \\
Total & 49 & 100,0 & 97 & 100,0 \\
\hline
\end{tabular}

The frequencies (n) and percentages (\%) of the sports they were involved in other than soccer by age group (Table 1). 
Table 2. The participants' physical and demographic characteristics and motor skills test measurement results

\begin{tabular}{|c|c|c|c|c|c|c|c|c|c|}
\hline \multirow{2}{*}{ Parameters } & & \multicolumn{4}{|c|}{ 10-12 age group } & \multicolumn{4}{|c|}{ 13-15 age group } \\
\hline & & $\mathrm{n}$ & $\mathrm{x} \pm \mathrm{sd}$ & md. \pm sd. & $\mathrm{p}$ & $\mathrm{n}$ & $\mathrm{x} \pm \mathrm{sd}$ & md. \pm sd. & $\mathrm{p}$ \\
\hline \multirow{2}{*}{ Age (years) } & $\mathrm{SAO}$ & 32 & $11,09 \pm 0,82$ & \multirow{2}{*}{$-0,02 \pm 0,25$} & \multirow{2}{*}{0,91} & 54 & $14,07 \pm 0,87$ & \multirow{2}{*}{$-0,23 \pm 0,17$} & \multirow{2}{*}{0,20} \\
\hline & OS & 17 & $11,12 \pm 0,86$ & & & 43 & $14,30 \pm 0,80$ & & \\
\hline \multirow{2}{*}{ Height $(\mathrm{cm})$} & SAO & 32 & $144,81 \pm 8,50$ & \multirow{2}{*}{$-0,01 \pm 2,57$} & \multirow{2}{*}{1,00} & 54 & $161,56 \pm 11,93$ & \multirow{2}{*}{$-0,47 \pm 2,30$} & \multirow{2}{*}{0,84} \\
\hline & OS & 17 & $144,82 \pm 8,71$ & & & 43 & $162,02 \pm 10,38$ & & \\
\hline \multirow{2}{*}{ Weight $(\mathrm{kg})$} & $\mathrm{SAO}$ & 32 & $37,19 \pm 5,58$ & \multirow{2}{*}{$-2,40 \pm 1,96$} & \multirow{2}{*}{0,54} & 54 & $50,91 \pm 10,37$ & \multirow{2}{*}{$-1,09 \pm 2,05$} & \multirow{2}{*}{0,59} \\
\hline & OS & 17 & $39,59 \pm 8,07$ & & & 43 & $52,00 \pm 9,56$ & & \\
\hline \multirow{2}{*}{ BMI $\left(\mathrm{kg} / \mathrm{m}^{2}\right)$} & SAO & 32 & $17,64 \pm 1,39$ & \multirow{2}{*}{$-1,14 \pm 0,57$} & \multirow{2}{*}{$\mathbf{0 , 0 5 *}$} & 54 & $19,30 \pm 1,94$ & \multirow{2}{*}{$-0,35 \pm 0,40$} & \multirow{2}{*}{0,38} \\
\hline & OS & 17 & $18,79 \pm 2,61$ & & & 43 & $19,65 \pm 1,95$ & & \\
\hline \multirow{2}{*}{$\begin{array}{l}\text { Age of performing sports } \\
\text { (year) }\end{array}$} & $\mathrm{SAO}$ & 32 & $2,88 \pm 1,54$ & \multirow{2}{*}{$0,23 \pm 0,46$} & \multirow{2}{*}{0,60} & 54 & $4,81 \pm 2,11$ & \multirow{2}{*}{$0,47 \pm 0,42$} & \multirow{2}{*}{0,22} \\
\hline & OS & 17 & $2,65 \pm 1,54$ & & & 43 & $4,35 \pm 1,99$ & & \\
\hline \multirow{2}{*}{ Sprint $10 \mathrm{~m}$ (sec) } & SAO & 32 & $2,17 \pm 0,12$ & \multirow{2}{*}{$-0,12 \pm 0,04$} & \multirow{2}{*}{$\mathbf{0 , 0 0 * *}$} & 54 & $1,95 \pm 0,13$ & $-005+0.03$ & 012 \\
\hline & OS & 17 & $2,29 \pm 0,15$ & & & 43 & $2,00 \pm 0,15$ & $-0,00 \pm 0,03$ & 0,12 \\
\hline Sprint $30 \mathrm{~m}(\mathrm{sec})$ & $\mathrm{SAO}$ & 32 & $5,42 \pm 0,32$ & $-0.37+0.10$ & $0.00 * *$ & 54 & $4,77 \pm 0,37$ & $-0.15+0.08$ & 0.11 \\
\hline & OS & 17 & $5,78 \pm 0,35$ & $-0,5 / \pm 0,10$ & & 43 & $4,92 \pm 0,45$ & $-0,1 J \pm 0,00$ & \\
\hline ro-agility 1 st Turn ( $\mathrm{sec}$ ) & SAO & 32 & $3,29 \pm 0,24$ & -0.07 & & 54 & $2,80 \pm 0,21$ & & \\
\hline Pro-dgmly ist rum (sec) & OS & 17 & $3,36 \pm 0,20$ & $-0,0 / \pm 0,0 /$ & 0,34 & 43 & $2,91 \pm 0,24$ & $-0,11 \pm 0,00$ & 0,0 \\
\hline $\mathrm{sec})$ & $\mathrm{SAO}$ & 32 & $6,36 \pm 0,46$ & & 03 & 54 & $5,40 \pm 0,39$ & & \\
\hline 1 & OS & 17 & $6,49 \pm 0,36$ & & 0,31 & 43 & $5,59 \pm 0,45$ & 39 & \\
\hline Horizontal Jumn (meter) & $\mathrm{SAO}$ & 32 & $139,59 \pm 20,46$ & $18.95+5.95$ & $0.00 * *$ & 54 & $191,81 \pm 27,06$ & $61+5$ & $0.05 *$ \\
\hline 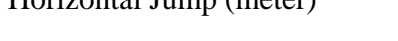 & OS & 17 & $120,65 \pm 18,57$ & 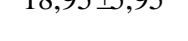 & & 43 & $180,21 \pm 29,67$ & $11,01 \pm J, 11$ & 0,02 \\
\hline 20 meter Shuttle Run (meter) & $\mathrm{SAO}$ & 32 & $1038,75 \pm 316,39$ & $34228+8502$ & $0.00 * *$ & 54 & $1795,56 \pm 394,81$ & $38160+87.95$ & $0.00 * *$ \\
\hline & OS & 17 & $696,47 \pm 204,48$ & & & 43 & $1413,95 \pm 471,30$ & ( & \\
\hline Balance (Number) & SAO & 32 & $5,69 \pm 2,24$ & $-1,25 \pm 0,67$ & $\mathbf{0 , 0 3 *}$ & 54 & $4,09 \pm 1,26$ & $-1,07 \pm 0,28$ & $\mathbf{0 , 0 0} * *$ \\
\hline & OS & 17 & $6,94 \pm 2,22$ & $-1,2 J \pm 0,01$ & $\mathbf{0 , 0 \boldsymbol { J }}$ & 43 & $5,16 \pm 1,45$ & & \\
\hline
\end{tabular}

$* * \mathrm{p}<0.01, * \mathrm{p}<0.05, \mathrm{SAO}$ : soccer and other sports, OS: only soccer, $\mathrm{x}$ : mean, md: mean difference

The statistical analysis found that there was a statistically significant difference $(p<0.05)$ between the measurement results of the participants in the 10-12 age group who were involved into sports other than soccer and of those who were involved only in soccer in the 10 meter and 30 meter sprint, the horizontal jump, 20 meter shuttle run test, aerobic endurance, and the flamingo balance test to the advantage of the group that was involved in both soccer and other sports, while the differences between the other parameters were not significant ( $p>0.05)$. In the 13-15 age group, there was a statistically significant difference between the measurement results of the participants who were involved only in soccer and of those who were involved in both soccer and other sports in pro-agility, the horizontal jump, the 20 meter shuttle run test, and the flamingo balance test to the advantage of the group that was involved in other sports in addition to soccer $(\mathrm{p}<0.05)$. The differences between the other parameters were not significant $(\mathrm{p}>0.05)$ (Table 2$)$.

\section{Discussion and Conclusion}

This study examined the effects of sports activities other than soccer on 10-15-year-old soccer players' motor skills. It compared the motor skill performances of the children who played only soccer and those involved in other sports activities in addition to soccer in an attempt to determine the differences and similarities between them. The researcher found that there were no studies in the relevant literature that compared the performance characteristics of athletes who were involved in only one sport and those involved in multiple sports or evaluated the relations between all of the sports. On the other hand, independent studies have been found on these subjects, and this research is supported by other findings in the literature.

A 14-year study that was conducted in East Germany divided a large sample into two groups. The first group maintained a training program that was specific to their sport, while the second group aimed for versatile development with a broader training program that was not specific to the sport. The study results demonstrated that the athletes in the first group (following a branch-specific training program) had a better development in the short term. However, they got in a period of regression around the age of 18 because they got tired of what they were doing. The results also showed that the athletes in the second group in the versatile training program developed regularly and consistently, and they had top productivity especially after the age of 18 . In addition, the athletes in the second group had longer sports careers (Harre, 1982). Another study in Russia found that successful Russian athletes engaged in different sports (e.g., soccer, skiing, shooting, cross country running and swimming) when they were young rather than practicing only one sport or performing sport-specific training (Colibaba and Bota, 1998). Carlson (1988) conducted a similar study that inquired the past and development levels of Swedish tennis players who were successful in the international arena. Carlson (1988) determined that the first group in the study were successful at sports when they were young, yet could not 
maintain this success after they turned 18. In contrast, the players in the second group attended at their early ages the training programs that addressed versatile development, and were involved in a variety of sports activities. That study found that the sport-specific and strict training sessions at early ages force athletes and actually prevent success later in their careers.

This study found no significant differences between the age and height-weight measurements of the two groups. Based on the measurement results, the OS and SAO groups had a homogeneous structure in both age groups.

The study examined the BMI values of the groups and the statistical differences between them. The difference between the BMI values of the 10-12 age group was statistically different to the advantage of the SAO group. In the 13-15 age group, the mean values of BMI were lower than those of the SAO group, but the difference was not statistically significant $(\mathrm{p}>0.05)$. In both age groups, the BMI values were consistent with the relevant literature (Diker and Müniroğlu, 2016; Yüksek et al, 2017).

The study conducted 10 meter and 30 meter sprint tests to determine the speed performances of the groups and the statistical differences between them. The results indicated that the differences between both 10 meter and 30 meter sprint test measurements in the 10-12 age group were statistically significant to the advantage of the SAO group $(\mathrm{p}<0.01)$. In the 13-15 age category, the SAO group was faster, but the difference between the OS and SAO groups' measurements was not statistically significant (Table 2). As commonly known, speed ability is a hereditary trait, but it can be improved by conscious training (Sevim, 2006). The skill to show fast reactions to unexpected developments in soccer is directly related to speed performance, since speed in soccer is more complicated than covering the distance between two points in the shortest time possible. Players can use speed to pass or block opponents, to gain possession of the ball or to protect the ball (Eniseler, 2010). Therefore, the other sports that also attribute importance to speed performance and contribute to its development as well in fact help the development of speed performance in soccer because there is a need for speed at certain rates in all sports (Dündar, 2015). Previous studies proved that certain sports branches in addition to soccer (e.g. basketball, swimming) contribute to speed development as well (Atan et al, 2016; Bavlı, 2012; Saygın, 2001; Yılmaz, 2012; Yılmaz et al, 2004). Akçakaya's (2009) study of 45 male athletes aged 19 and 20 who were interested in soccer, basketball and track and field reported that athletes' speed skills had similar characteristics. Similarly, Duyul's (2005) study of 46 male athletes interested in soccer, handball and volleyball reported that there were no statistically significant differences in the 10 meter speed performances between the soccer players and volleyball and handball players; there was also no significant difference in the $20 \mathrm{~m}$ speed performances between soccer and handball players ( $\mathrm{p}>0.05)$. The speed performances of the athletes were similar. Atan et al, (2012) conducted a study with 60 female athletes in the 20 age group that were volleyball, basketball, and soccer players. They found that the speed performances of the athletes were similar to each other, and there was no statistically significant difference between them. Albay et al, (2008) did a study of 46 male soccer, handball and volleyball players and found no statistically significant difference between the $10 \mathrm{~m}$ speed performances of soccer players versus volleyball and handball players, or the $20 \mathrm{~m}$ speed performances of soccer players and handball players ( $p>0.05$ ) Spahi et al, (2016) carried out a study with 48 basketball players with a mean age of 17, and found that athletics and fitness practices that accompanied basketball training had the potential to create a considerable development in athletes' speed competences.

The study performed a pro-agility test to determine the quickness of the groups and the statistical differences between them. The test results were statistically significant in the 13-15 age group to the advantage of the SAO group ( $\mathrm{p}<0.05)$. In the 10-12 age category, the mean values of the measurement were lower in the SAO group, but the difference between the two groups was not statistically significant (Table 2). In a soccer game, athletes always use speed skills as non-linear, sometimes as divergent, and quickness performance plays an important role at this stage (Eniseler, 2010). This skill allows athletes to move accurately and with less effort (Sevim, 2006). The abilities to resist stimuli from the environment, to change direction quickly and to reaccelerate are very important in all sports (Bloomfield et al, 2007; Gabbett, Kelly and Sheppard, 2008; Little and Williams, 2005). The ability to achieve higher performance with less effort, quicker position changes, faster adaptation to new positions and the ability to change places or move explosively in short distances are key criteria for achieving success not only for a single sport, but for all sports. If these skills are learned, they will be important acquisitions for all sports, not for only one of them. In this respect; Kizllet et al, (2010) reported a significant improvement in the speed skills of athletes in their 8-week study of 24 basketball players in the 10-12 age group. Similarly, Wroble and Moxley (2001) conducted a study with 57 soccer players in 9-11 age group, 18 of whom were involved in winter sports in addition to soccer, and reported that the group performing both soccer and winter sports had more developed performances in agility and quickness. Yılmaz et al. (2004) accompanied children with autism during their 10-week swimming exercises, and found that there was important development in children's agility performances. Spahi et al. (2016) carried out a study with 48 basketball players whose mean age was 17 . They determined that athletics and fitness training sessions that were maintained in addition to basketball training could help important development in athletes' agility competences. 
This study's horizontal jump test was used to determine the statistical difference between the groups' vertical and horizontal axial leg power, balance and coordination. The difference was found to be statistically significant in favor of the SAO group $(\mathrm{p}<0.01)$ (Table 2).Yörükoğlu and Koz (2007) reported a significant improvement in the horizontal jump performance of athletes after 5 months of study with 17 basketball players. Karadenizli and Özkamçı (2015) did a study with 30 soccer and handball players whose mean age was 23 and reported that there was no significant difference between their horizontal jump test results. In other words, the athletes had similar performances. Likewise; İri, Yilmaz and Aktuğ (2016) studied with 66 soccer and handball players with a mean age of 22 and reported that there was no significant difference between their horizontal jump results. Other studies of this subject have demonstrated that sports other than soccer also have positive effects on horizontal jumping skill. Thus, soccer may also affect horizontal jumping ability positively.

This study conducted a 20 meter shuttle run test to determine the endurance performances of the groups and the statistical differences between them. The results indicated that the differences between 20 meter shuttle run aerobic power test measurements were statistically significant to the advantage of the SAO group $(\mathrm{p}<0.01)$ (Table 2). Previous studies have shown that soccer positively affects aerobic capacity (Altın and Kaya, 2012; Cicioğlu, Ocak and Günay, 2001; Saygin, 2001). On the other hand, İri et al. (2016) reported that handball improved aerobic endurance significantly in addition to soccer. Yörükoğlu and Koz (2007) reported at the end of a 5-month study that there was a significant development in the athletes' VO2 max performances. Y1lmaz (2012) conducted a study with 13 swimmers for 8 weeks, and reported at the end of the study that there was considerable improvement in athletes'aerobic power capacities. Spahi et al. (2016) determined that athletics and fitness training that was performed along with basketball training sessions could lead to notable improvement in athletes' endurance competencies. The relevant studies examined by this research support this study because they show the positive effect of different sports on aerobic capacity, and, accordingly, their positive contribution to the aerobic power that is required for soccer.

The researcher performed a flamingo balance test to determine the groups' balance performances and the statistical differences between them. The results of the test measurement were analyzed, which revealed that the difference between the measurements was statistically significant to the advantage of the SAO group ( $<<0,05)$ (Table 2). Past studies of this subject showed that basketball had positive effects on balance performance (Atan et al., 2016; Kizılet et al., 2010; Tetik et al., 2013). Sucan, Y1lmaz, Can and Süer (2005) carried out a study with 40 participants, 20 of whom were soccer players, and reported that regular physical exercise could improve balance performance significantly. Similarly, Erkmen et al, (2007) did a study with 35 football players, basketball players and gymnasts and reported that the balance performance of the football and basketball players were close to each other. In another study by Yilmaz et al. (2004), reported that autistic children significantly improved their balance performance after 10 weeks of swimming exercises. Previous studies have demonstrated that balance can be improved by involvement in a variety of sports, which means that soccer can also contribute to its improvement.

Previous studies have also shown that there was no significant difference between the motor skills of children who engaged in different sports, but that they had similar motor development. The researcher believes this is due to the fact that the motor skills examined in these studies are important in all sports, and that the various sports contributed to them. Even though the highlighted motor skill requirements are different in each sport by their nature (e.g., endurance for long-distance running, speed for sprints, physical strength for weightlifting), each sport also involves the other motor parameters. For instance, quickness and endurance are as important as speed in a game of soccer. For this reason, performing different sports, especially at early ages, will train and improve the motor skills that are dominant in that sport with enriched and different methods in addition to the other motor characteristics. This study was conducted in a season that included no soccer competition. For this reason, the participants who played only soccer were doing less training at the time of the study, while those who were involved in sports other than soccer were training more frequently. This may have contributed to the results of this study.

The parameters of BMI, the sprints, the horizontal jump, endurance and balance were more developed in the 10-12 age group to the advantage of the SAO group, while quickness, the horizontal jump, endurance and balance parameters were more developed in the 13-15 age group, again to the advantage of the SAO group. These results demonstrate that children's engagement in multiple sports at an early age and including forms of play that feature the fundamental skills of different sports in their training programs will positively contribute to the development of their motor skills. Thus, children's motor skills and coordination will be enhanced if their trainers implement training programs that are supported with educational games that include the movement skills of other sports along with their main sport. We also believe that the results of this research will help the trainers and coaches of young athletes with preparing children's training programs and directing plans and programs. 


\section{References}

Akçakaya, İ. (2009). Compare anthropometric and motoric features of some players are in the trakya university athletics, basketball and football teams (Unpublished master's thesis). Trakya University, Edirne, Turkey.

Albay, M., Tutkun, E., Ağaoğlu, Y., Canikli, A., \& Albay, F. (2008). The investigation of some motor values and antropometric characteristics of handball, volleyball and football university teams.Spormetre Journal of Physical Education and Sport Sciences, 6(1), 13-20.

Altın, M., \& Kaya, Y. (2012). The effect of intensity interval training method on aerobic and anaerobic power in football players aged 14-16. Selçuk University Journal of Physical Education and Sport Science, 14(2), 253-256.

Atan, T., Ayyıldız, T., \& Ayyıldız, P. A. (2012). Some physical fitness values of female athletes engaged in different team sport branches. Selçuk University Journal of Physical Education and Sport Science, 14(2), 277-282.

Atan, T., Eliöz, M., Çebi, M., Ünver, Ş., \& Atan, A. (2016). Investigation of the effect of basketball training on motoric skills of the educable mentally retarded children. Journal of Sports and Performance Researches, 7(1), 29-35.

Bavl1, Ö. (2012). Investigation the effects of combined plyometrics with basketball training on some biomotorical performance. pamukkale journal of sport sciences, 3(2), 90-100.

Bloomfield, J., Polman, R., O'donoghue, P., \& Mcnaughton, L. (2007). Effective speed and agility conditioning methodology for random intermittent dynamic type sports. Journal of Strength and Conditioning Research, 21(4), 1093-100.

Bompa, T., \& Haff, G. (2015). Dönemleme: Antrenman kuramı ve yöntemi(5th ed.). (Bağırgan T.).Ankara: Spor Press and Bookstore.

Carlson, R. (1988). The socialization of elite tennis players in Sweden: An analysis of the players' backgrounds and development. Sociology of Sport Journal, 5(3), 241-256. https://doi.org/10.1123/ssj.5.3.241

Cicioğlu, İ., Ocak, Y., \& Günay, M. (2001). The effects of 6 weeks preparation phase training on some physical and physiological parameters of proffessional soccer players. Journal of Physical Education and Sport Sciences, 1(2), $37-41$.

Colibaba, E. D., \& Bota, I. (1998). Jocurile sportive: teoria si medodica. Bucureşti: EdituraAldin.

Dardouri, W., Gharbi, Z., Selmi, M. A., Sassi, R. H., Moalla, W., Chamari, K., \& Souissi, N. (2014). Reliability and validity of a new Maximal anaerobic shuttle running test. International Journal of Sports Medicine, 35(04), 310-315.

Diker, G., \& Müniroğlu, S. (2016). Investigation of physical features of young players who are between 8-14 according to age. Ankara University Faculty of Sport Sciences, 14(1), 45-52.

Dündar, U. (2015). Antrenman teorisi (9th ed.). Ankara: Nobel Akademik Publishing.

Duyul, M. (2005). Comparation of effects to succes of motor values and antropometrik characteristics of handball, volleyball and football player university teams (Unpublished master's thesis). Ondokuz Mays University, Samsun, Turkey.

Eniseler, N. (2010). Bilimin ışığında futbol antrenmanı (1st ed.). Manisa: Birleşik Printing.

Erkmen, N., Suveren, S., Göktepe, A., \& Yazıcıoğlu, K. (2007). The comparison of balance performance of the athletes who are in different branches.Spormetre Journal of Physical Education and Sport Sciences, 3, 115-122.

Gabbett, T., Kelly, J., \& Sheppard, J. (2008). Speed, change of direction speed, and reactive agility of rugby league players.The Journal of Strength \& Conditioning Research, 22(1), 174-181.

https://doi.org/10.1519/JSC.0b013e31815ef700

Harre, D. (1982). Training slehre. Berlin, Germany: Sportverlag.

İri, R., Y1lmaz, A., \& Aktuğ, Z. (2016). The comparison of physical fitness levels and motoric features of elite footballers and handball players. Journal of Sports and Performance Researches, 8(1), 19-25.

James, R. M., Allen, W. J., James, G. D., \& Dale, P. M. (2005). Measurement and evaluation in human performance. USA: Human Kinetics.

Karadenizli, Z., \& Özkamçı, H. (2015). Comparison of some physical and physiologic properties of soccer players and badminton players of 10-12 years old group. Journal of Human Sciences, 17(2), 47-58.

Kızılet, A., Atılan, O., \& Erdemir, İ. (2010). The effect of different strength trainings on speed and jumping ability among the basketball players aged 12 and 14. Journal of Physical Education and Sport Sciences, 12(2), 44-57. 
Leger, L., \& Lambert, J. (1982). A maximal multistage $20 \mathrm{~m}$ shuttle run test to predict VO2 Max. European Journal of Applied Physiology and Occupational Physiology, 49(1), 1-12.https://doi.org/10.1007/BF00428958

Little, T., \& Williams, A. (2005). Specificity of acceleration, maximum speed, and agility in professional soccer players. The Journal of Strength \& Conditioning Research, 19(1), 76-78.

Maulder, P., \& Cronin, J. (2005). Horizontal and vertical jump assessment: reliability, symmetry, discriminative and predictive ability. Physical Therapy in Sport, 6(2), 74-82. https://doi.org/10.1016/j.ptsp.2005.01.001

Mcguigan, M. (2000). Essentials of strength training and conditioning (4th ed.). Australia: University of New South Wales Press.

Muratlı, S., Kalyoncu, O., \& Şahin, G. (2011). Antrenman ve müsabaka. İstanbul: Kalyoncu Spor Danışmanlık San. Tic. Ltd. Ști.

Saygın, Ö. (2001). The effects of training programme in preparation period on some physicll and physiological parameters of professional soccer players. Journal of Physical Education and Sport Sciences, 1(3), 102-107.

Sevim, Y. (2006). Basketbol teknik taktik antrenman (6th ed.). Ankara: Nobel Press.

Spahi, A., Bilali, A., \& Jarani, J. (2016). The role of a training program based on fitness and athletics, to improve the cardiorespiratory. European Journal of Health \& Science In Sports , 11-15.

Sucan, S., Yilmaz, A., Can, Y., \& Süer, C. (2005). The different balance parameters evaluation of the active soccer players. Journal of Health Sciences, 14(1), 36-42.

Tetik, S., Koç, M., Atar, Ö., \& Koç, H. (2013). An analysis of the correlation between static balance performance and game value scale in basketball players. Turkish Kick Boxing Federation Journal of Sport Science, 6(1), 9-18.

Tsigilis, N., Douda, H., \& Tokmakidis, S. P. (2002). Test-retest reliability of the Euro fit test battery administered to University students. Perceptual and motor skills, 95(3), 1295-1300. https://doi.org/10.2466/pms.2002.95.3f.1295

Wood, R. (2008a). Speedor sprint testing. Retrieved from http://www.topendsports.com/testing/tests/sprint.htm

Wood, R. (2008b). Flamingo balance test. Retrieved from http://www.topendsports.com/testing/tests/balance-flamingo.htm

World Medical Association. (2008). Declaration of Helsinki-Ethical principles for medical research involving human subjects. Retrieved from

https://www.wma.net/policies-post/wma-declaration-of-helsinki-ethical-principles-for-medical-research-involvinghuman-subjects/

Wroble, R., \& Moxley, D. (2001). He effect of winter sports participation on high school football players: strength, power, agility, and body composition. The Journal of Strength \& Conditioning Research, 15(1), 132-135.

Yllmaz, I., Yanardag, M., Birkan, B., \& Bumin, G. (2004). Effects of swimming training on physical fitness and water orientation in autism. Pediatrics International, 46(5), 624-626. https://doi.org/10.1111/j.1442-200x.2004.01938.x

Y1lmaz, T. (2012). The effect of 8-week swimming exercises on adolescents aerobic powers, respiratory function and body balance (unpublished doctoral dissertation). Selçuk University, Konya, Turkey.

Yörükoğlu, U., \& Koz, M. (2007). The effect of sport school and sport club trainings on physical, physiological and antrophometric properties of boys whose ages range from 10-13. Spormetre Journal of Physical Education and Sport Sciences, 2, 79-83.

Yüksek, S., Hatipoğlu, Ö., Ayan, V., \& Ölmez, C. (2017). The relationship between 50 meter sprint and 25 meter free style swimming performances in 9-12 ages swimmers. Turkiye Klinikleri Journal of Sports Sciences, 9(2), 57-64.https://doi.org/10.5336/sportsci.2016-54024

Zorba, E. (2001). Fiziksel Uygunluk. Muğla: Gazi Bookstore.

\section{Copyrights}

Copyright for this article is retained by the author(s), with first publication rights granted to the journal.

This is an open-access article distributed under the terms and conditions of the Creative Commons Attribution license which permits unrestricted use, distribution, and reproduction in any medium, provided the original work is properly cited. 